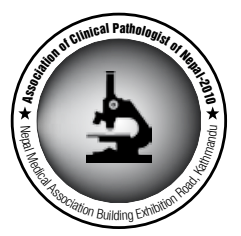

\title{
Analysis of mediastinal lesions: a study of 27 cases
}

\author{
Karki $\mathrm{S}^{1}$, Chalise $\mathrm{S}^{1}$ \\ ${ }^{1}$ Department of pathology, Institute Of Medicine, Tribhuwan University Teaching Hospital, Kathmandu, Nepal
}

\author{
Keywords: \\ Mediastinum; \\ Germ cell tumor; \\ Thymoma; \\ Non Hodgkin Lymphoma
}

\begin{abstract}
Background: Mediastinum is a site of non-neoplastic and neoplastic lesions, many of which present as mediastinal masses. The purpose of this study was to study our institutional experience of mediastinal lesions on fine needle aspiration cytology or biopsy.

Materials and Methods: This was a retrospective study of 27 patients, who had undergone fine needle aspiration cytology or biopsy for mediastinal lesions from April 2009 to November 2010 in the Department of Pathology, Institute of Medicine, Tribhuwan University Teaching Hospital. All details of the patients pertinent clinical history was obtained from case record file in the department.

Results: Out of 27 cases, 18 cases (66.6\%) were benign and 7 (26\%) were malignant and $2(7.4 \%)$ were inconclusive. Among the malignant lesions, primary tumors constituted $71.5 \%$ of cases while metastases were $28.5 \%$. Most of the lesions were seen in the anterior compartment followed by the posterior compartment. Age range was 4 months to 70 years with a mean age of 35.5 years. Thymoma ( 8 cases) was the commonest lesion seen in mediastinum followed by germ cell tumor and neurogenic tumor.
\end{abstract}

Conclusion: Benign mediastinal lesions are more common than malignant lesions with thymoma being the most commonly diagnosed mediastinal lesion.

\section{INTRODUCTION}

The mediastinum occupy the thoracic cavity between the pleural cavities and the lungs laterally, sternum anteriorly and the vertebral column posteriorly and from the thoracic inlet down to the diaphragm. The mediastinum contains many vital anatomic structures. It is a site of non-neoplastic

\section{Correspondence:}

Dr. Shovana Karki, MD

Dept of pathology, Institute Of Medicine, Tribhuwan University Teaching Hospital, Kathmandu, Nepal

Email: shovana_karki@hotmail.com and neoplastic lesions, benign and malignant, primary and metastatic, many of which present as mediastinal masses. ${ }^{1}$

Although clinical data, location in the mediastinum and radiological findings all aid in narrowing the differential diagnosis, a tissue diagnosis helps in guiding management of mediastinal lesions.

Mediastinum is divided into several compartments and location of a lesion also provides useful information in formulating a differential diagnosis. ${ }^{2}$ Due to proximity of the 
mediastinum to heart and great vessels, careful assessment is necessry. ${ }^{3}$ In addition there is a complexity and difficulty in diagnosing mediastinal lesions on Fine Needle Aspiration Cytology (FNAC) or even in surgical biopsy material. ${ }^{1}$

The purpose of this study was to study our institutional experience of mediastinal lesions.

\section{MATERIALS AND METHODS}

This was a retrospective study of 27 patients, who had undergone FNAC or biopsy for mediastinal lesions from April 2009 to November 2010 in the Department of Pathology, Institute of Medicine, Tribhuwan University Teaching Hospital. All details of the patients pertinent clinical history was obtained from case record file in the department.

The FNAC was performed using a 23-gauge needle attached to a $10 \mathrm{ml}$ disposable syringe. Aspirates were smeared on clean glass slides, wet fixed or air dried and stained by papanicolaou (PAP) and May-Grunwald-Giemsa (MGG) stains. The surgical specimens were fixed in $10 \%$ formalin, then routinely processed and stained by Haematoxylin and Eosin (HE) stain.

\section{RESULTS}

Out of 27 patients included in the study, 10 had FNAC diagnosis and 17 had tissue diagnosis. Two patients with FNAC had tissue biopsy also. One was a case of thymoma which correlated with biopsy whereas other case was mature cystic teratoma which showed inconclusive tissue diagnosis. In these two cases, diagnosis of FNAC was analyzed with exclusion of tissue biopsy.

Age range of these patients was from 4 months to 70 years with a mean age of 35.5 years. Thirteen were males and 14 were females with (M: $\mathrm{F}=1: 1.07)$.

Nature of mediastinal lesion is shown in Table 1. Age wise distribution of the patients along with diagnosis is shown in Table 2.

Different lesions were diagnosed according to locations. Most of the cases were localized in anterior mediastinum. There were 8 cases of thymoma (fig. 1A, B and C), one case of thymic carcinoma (fig. 2) and one case of involutaional changes. Other cases in anterior mediastinum were 2 cases of Non Hodgkin Lymphoma (fig. 3) and 2 cases were of metastatic carcinoma ( squamous cell carcinoma and small cell carcinoma). One case showed necrotizing granulomaotous lymphadenitis and was suspected for tuberculosis whereas two other cases were inconclusive. In the middle mediastinum one case of bronchogenic cyst was diagnosed. In the posterior mediastinum, there were one case of mixed germ cell tumor (teratoma with embryonal carcinoma), two cases of schwannoma and lymphangioma, neurofibroma and benign fibrous histiocytoma (fig. 4) one case each.

\section{DICUSSION}

Primary mediastinal tumors are uncommon representing, about $3 \%$ of tumors within the chest wall. ${ }^{4-5}$ As many as 25

$\begin{aligned} & \text { Table 1: Distribution of cases according to nature of } \\
& \text { lesion }\end{aligned}$
\begin{tabular}{lcc}
\hline Nature of Lesion & $\begin{array}{c}\text { Number of } \\
\text { cases }\end{array}$ & Percentage (\%) \\
\hline Benign & 18 & 66.6 \\
\hline Malignant & 7 & 26 \\
\hline Inconclusive & 2 & 7.4 \\
\hline Total & $\mathbf{2 7}$ & $\mathbf{1 0 0}$ \\
\hline
\end{tabular}

Table 2: Diagnosis of lesions in relation to age distribution.

\begin{tabular}{|c|c|c|c|c|c|c|c|c|c|}
\hline \multirow{2}{*}{ Diagnosis } & \multicolumn{8}{|c|}{ Age range } & \multirow{2}{*}{ Total } \\
\hline & $0-9$ & $10-19$ & $20-29$ & $30-39$ & $40-49$ & $50-59$ & $60-69$ & $70-79$ & \\
\hline Thymic lesion & & & 1 & 1 & 3 & 3 & & 2 & 10 \\
\hline Germ cell tumor & 1 & 2 & & & & & & & 3 \\
\hline Neurogenic tumors & & & 1 & 1 & & 1 & & & 3 \\
\hline Lymphoid tumors & & 2 & & & & & & & 2 \\
\hline Sarcoma & & 1 & & & & & & & 1 \\
\hline Vascular tumor & & & & 1 & & & & & 1 \\
\hline Cyst & & & & & & 1 & & & 1 \\
\hline Mesenchymal & & & 1 & & & & & & 1 \\
\hline Others & 1 & & & & & & & & 1 \\
\hline Metastasis & & & & & 2 & & & & 2 \\
\hline Inconclusive & & & & 1 & & 1 & & & 2 \\
\hline Total & 2 & 5 & 3 & 4 & 5 & 6 & $\mathbf{0}$ & 2 & 27 \\
\hline
\end{tabular}



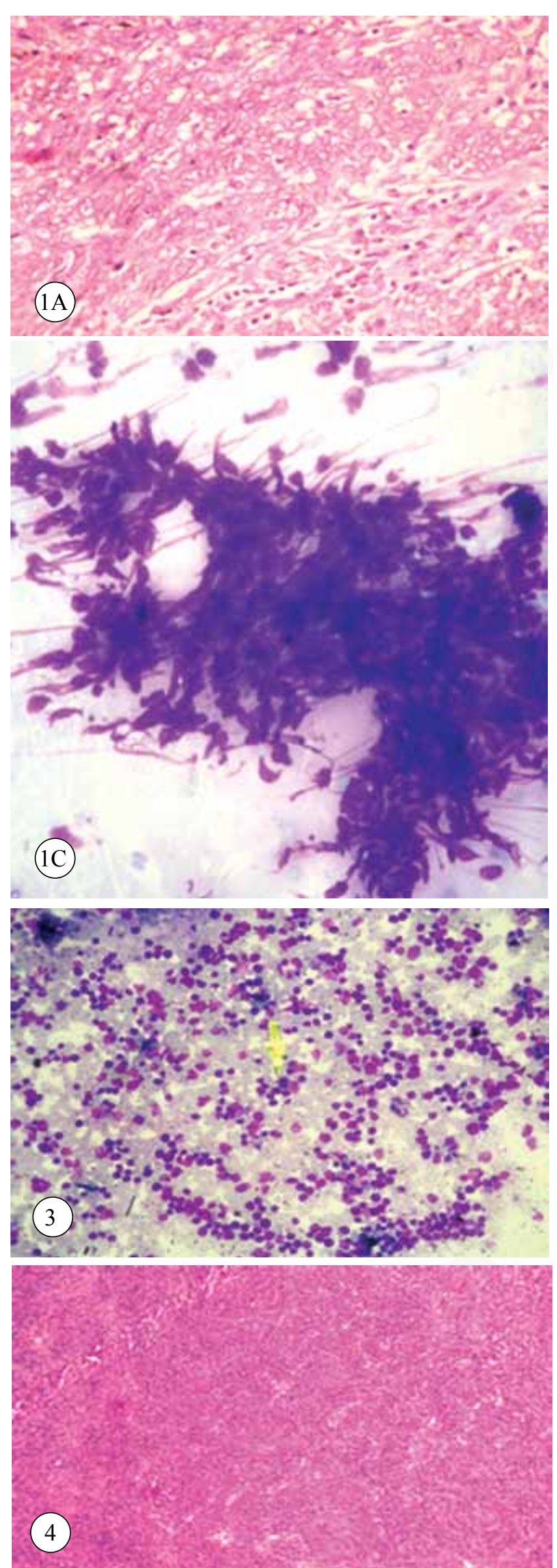
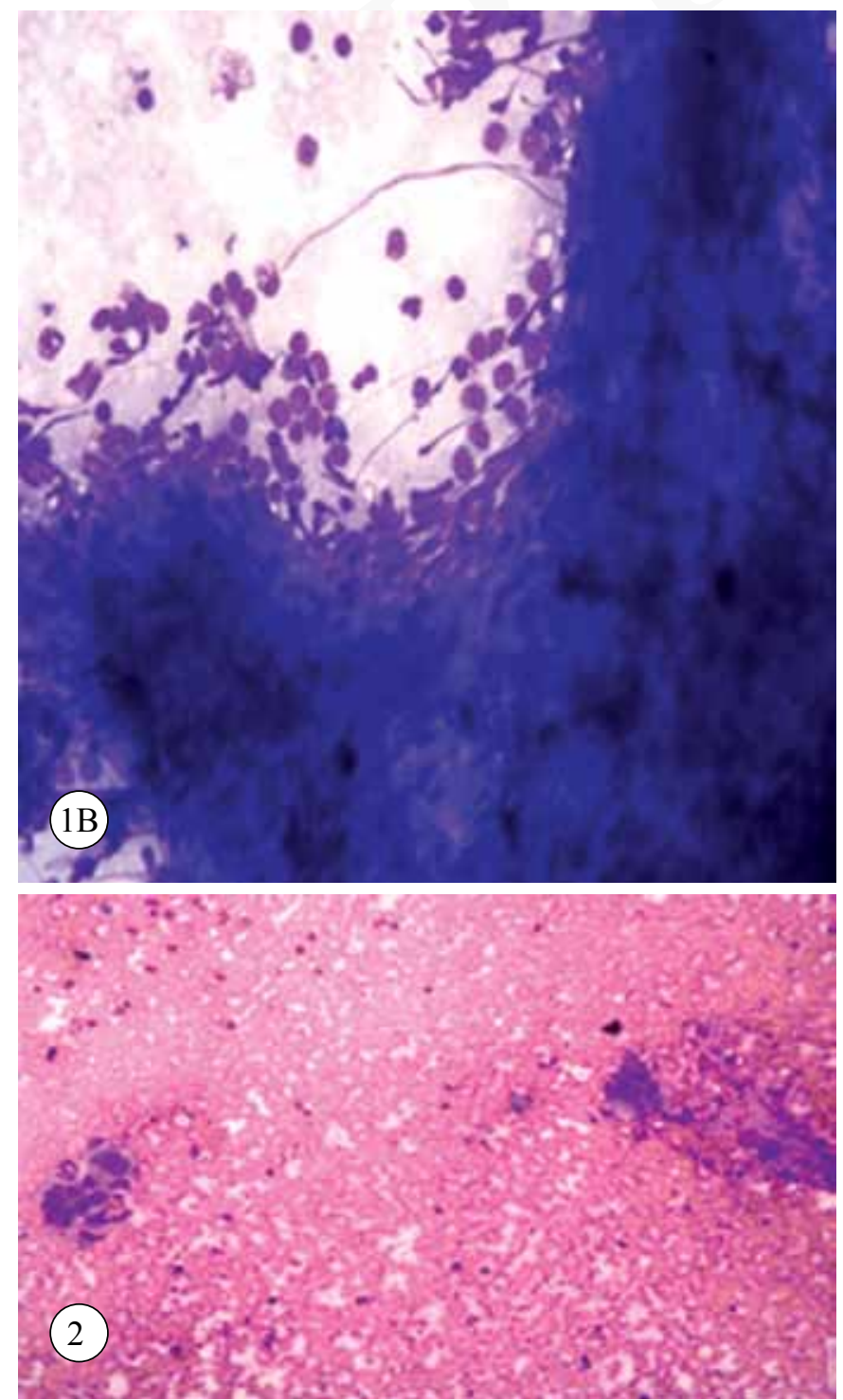

Figure 1A: Type B2 thymoma showing epithelial cells having vesicular nuclei with prominent nucleoli admixed with lymphocytes (HE stain, X400)

Figure 1B\&C: Type AB thymoma with epithelial cells (left) and spindle cells (right). (Giemsa stain, X400)

Figure 2: Thymic carcinoma showing atypical squamous cells with dense cytoplasm and hyperchromatic nuclei (HE stain, X400).

Figure 3: Non Hodgkin lymphoma, Lymphoblastic type showing frequent mitosis (arrowhead). (Giemsa stain, X400)

Figure 4: Spindle cells arranged in storiform pattern in benign fibrous histiocytoma.(HE stain, X100) 
to $40 \%$ of these lesions are malignant. ${ }^{4}$

In this study, $66.6 \%$ of the cases were benign, $26 \%$ were malignant and the rest were inconclusive. Adler et $\mathrm{al}^{6}$ and Jureb et $\mathrm{al}^{7}$ reported a higher incidence of about $72 \%$ prevalence of malignancy in their study.

The patient demographics in this study are similar to those in previous reported series, ${ }^{3,6}$ with a wide age range, 4 months-70 yrs. In a study by Takeda et $\mathrm{al}^{8}$, age range was from new born to 84 yrs with mean of 35.5 yrs. But their study had a slight male predominance in contrast to ours with a M:F ratio of 1.33:1. Other similar studies also showed higher male predominance.

Our study had a predominance of primary mediastinal lesions (23 cases, 92\%) while metastatic tumors accounted for only 2 cases $(8 \%)$ out of the diagnosed cases. In a study by Shabb et al, primary lesions were more common than metastasis in the mediastinum. ${ }^{1}$

Among the malignant category, $71.5 \%$ were primary and $28.5 \%$ were metastatic lesions. In other studies also primary malignant tumors were more common than metastatic lesions. $^{1}$

Majority of lesions had anterior mediastinal presentation, (19 cases, $70.3 \%$ ) followed by posterior mediastinum (7 cases, $25.9 \%$ ). In a study by Dubashi et al, majority of tumors was seen in the anterior mediastinum followed by posterior mediastinum. ${ }^{9}$

Germ cell tumor and NHL, lymphoblastic type was seen to occur in the first to second decade of life, whereas thymoma was seen commonly in fifth to sixth decade of life.In another study, lymphoma and germ cell tumors predominantly occurred in third to fifth decade of life and thymic neoplasms, in fifth decade. ${ }^{9}$

This study showed thymoma followed by germ cell and neurogenic tumours as common lesions of the mediastinum. While in another study by Shabb et al, lymphoma followed by metastatic tumors were the commonest lesions. ${ }^{1}$

Neurogenic tumors were commonly seen in the posterior mediastinum which is in accordance with other study. ${ }^{10}$ In the posterior mediastinum, a single case of high grade sarcoma was found in a young female. Other studies have reported sarcomas in $2 \%$ to $8 \%$ of primary malignant mediastinal tumors. ${ }^{4,5,11}$

In a 4 month old child, necrotisizing granulomatous lymphadenitis with possibility of Tuberculosis was reported in a lesion of the anterior compartment. Granulomatous inflammation was reported in anterior compartment in other studies too which turned out to be mostly tuberculosis and sarcoidosis. ${ }^{1,12}$

\section{CONCLUSION}

Benign mediastinal lesions are more common than malignant lesions with thymoma being the most commonly diagnosed mediastinal lesion followed by germ cell tumors and neurogenic tumors.

\section{REFERENCES}

1. Shabb NS, Fahl M, Shabb B, Haswani P, Zaatari G. Fine Needle aspiration of the mediastinum. A clinical, Radiological, Cytological and Histologic study of 42 cases. Diagn Cytopathol 1998;19:428-36.

2. Giesinger KR. Differential diagnostic pitfalls in fine needle aspiration biopsies of mediastinum. Diagn Cytopathol 1995;13:436-42

3. Powers CN, Silverman JF, Geisinger KR, Frable WJ. Fine needle aspiration biopsy of the mediastinum: a multi-institutional analysis Am J Clin Pathol 1996;105:168-73.

4. Rubush JL, Gardner IR, Boyd WC, Ehrenhaft JL. Mediastinal tumors: Review of 186 cases. J Thoracic Cardiovascular Surg 1973;65:21622.

5. Wongsangiem M, Tangthangtham A. Primary tumors of the mediastinum: 190 cases analysis (1975-1995). J Med Assoc Thai 1996 79:689-97.

6. Adler OB, Rosenberger A, Peleg H. Fine needle aspiration biopsy of mediastinal masses. Am J Roenterol 1983;140:893-6.

7. Jareb M, Krasovec M, Transthroracic needle biopsy of mediastinal and hilar lesions. Cancer 1977;40:1354-7.

8. Takeda S, Miyoshi S, Akashi A, Ohta M, Minami M, Okamura M et al. Clinical spectrum of primary mediastinal tumours: A comparision of adult and pediatric population at a single Japanese Institution. $\mathrm{J}$ Surg. Oncol 2003;83:24-30.

9. Dubashi B, Cyriac S, Tenali SG. Clinicopathological analysis and out come of primary mediastinal malignancies. A report of 91 cases from a single institute. Ann Thorac 2009;4:140-2.

10. Hoffman OA, Gillespie DJ, Aughenbaugh GL, Grown LR. Primary mediastinal neoplasma (other than thymoma). Mayo Clin Proc 1993;68:880-91.

11. Temes R, Chavex T, Mapel D et al. Primary mediastinal malignancies: Findings in 219 patients. West J Med 1999;170:161-6.

12. Pandey DK, Ahmad Z, Masood I, Singh SK, Jairajpuri. Role of Fine needle aspiration cytology in evaluating mediastinal masses. Lung India 2009;26:114-6. 